\title{
Wind power in modern power systems
}

\author{
Zhe CHEN ( $ه)$
}

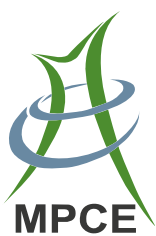

\begin{abstract}
In recent years, wind power is experiencing a rapid growth, and large-scale wind turbines/wind farms have been developed and connected to power systems. However, the traditional power system generation units are centralized located synchronous generators with different characteristics compared with wind turbines. This paper presents an overview of the issues about integrating largescale wind power plants into modern power systems. Firstly, grid codes are introduced. Then, the main technical problems and challenges are presented. Finally, some possible technical solutions are discussed.
\end{abstract}

Keywords Wind power plant, Grid code, Power control, Stability, Electricity market

\section{Introduction}

At present, renewable energy technologies are being rapidly developed worldwide, especially, wind power experiences a dramatic growth. The European Wind Energy Association (EWEA) has set a target to meet $28.5 \%$ European electricity needs with wind power by 2030 [1-3]. Denmark, which currently supplies more than $28 \%$ of electricity demand from wind, plans to realize a $50 \%$ share of electricity production by 2020 with wind power. China has very fast growth rate in recent years and

Received: 31 August 2012/Accepted: 8 January 2013/Published online: 5 July 2013

(C) The Author(s) 2013. This article is published with open access at Springerlink.com

Z. CHEN, Department of Energy Technology, Aalborg

University, 9220 Aalborg, Denmark

(凹) e-mail: zch@et.aau.dk

Z. CHEN, Sino-Danish Centre for Education and Research,

University of the Chinese Academy of Sciences (UCAS),

Beijing, China a great development plan [4]. Globally, wind turbines/wind power plants are being connected to various voltage levels of power systems, and they are distributed in low/medium voltage systems as well as directly connected to high voltage transmission grids.

Traditional power plants often use non-renewable fuels such as coal, oil and gas, which are the limited resources, and produce environmental pollution though the fossil fuel based generators with good controllability and availability, and rich experiences have been widely used in traditional power systems. The large-scale wind farms and other renewable energy based generation technologies are playing a more and more important role, and bring many changes to power grids. Therefore, the functions of traditionally centralized power plants will be significantly reduced in some areas.

However, the power produced by wind farms and other renewable energy technologies largely depends on natural conditions, such as wind speed, which are stochastic and cannot be precisely predicted. Furthermore, the generation technology is quite different from that used by the synchronous generator based conventional power plants. Power electronics are widely used as grid interface for modern wind turbines, either partially rated, such as doubly-fed induction generators (DFIGs), or fully rated with induction generators or synchronous generators [5]. The differences in energy source and generation technology present new technical problems and challenges, which make the operation and control of the power system more complicated than before [6,7]. Thus, the system would have more uncertainties and become more vulnerable if the problems and challenges could not be appropriately addressed.

This paper reviews the power system requirements on the wind power integration-grid code; introduces some technical problems and challenges of integrating large-scale wind 
power plants in modern power systems; discusses some possible technical solutions and methods.

\section{Grid codes and power system requirements}

In this section, the grid codes are briefly introduced, some contents of the Danish grid code [8] are used as illustrative examples.

In early days, when wind turbines were mostly connected to low voltage systems and wind power penetration level was low, the grid connection requirements or grid codes for wind turbines basically treated the wind power as negative load. However, the rapid growth of wind power penetration has made the grid codes updated continuously.

Integration of large-scale wind power may have significant impacts on power system security and economics. Stable, reliable and economical operation of power grids under the massive integration of wind power is a significant challenge. Grid codes specify the requirements that wind turbines must meet for grid connection. A grid code covers many technical aspects, in general, it includes steady state performances (frequency, voltage, active and reactive power, and power quality); dynamic performances (frequency gradients, start-stop, active power ramp rates, reactive power and voltage dynamic control, fault ride through, inertia, temporary overvoltage and protection); communication and control interface; simulation models, certification/verification; commissioning and performance verification.

A Danish grid code [8] is referred to illustrate some main aspects of the technical requirements in this section, including the regulation of frequency and voltage, control of active power and reactive power, fault ride-through capability, SCADA, etc.

\subsection{Operation range of frequency and voltage}

Maintaining power system frequency and voltage in the specified operating range is important for a power system operator. The intermittent nature of wind power production presents great challenge. In a conventional power system, the frequency is an indicator of imbalance between active power production and consumption, and the voltage is an indicator of imbalance between reactive power production and consumption. In power system normal operation, the frequency and voltage should be close to their nominal value in the specified ranges. Generation units should contribute to the frequency and voltage regulation by adjusting the amount of the generated active and reactive power. For larger wind turbines, operation outside the normal conditions may be allowed for specified time periods so that efforts can be made for restoring the normal operation. Figure 1 shows the active power production requirements under frequency/voltage variations for wind power plants between $25 \mathrm{~kW}$ and 1.5 MW [8].

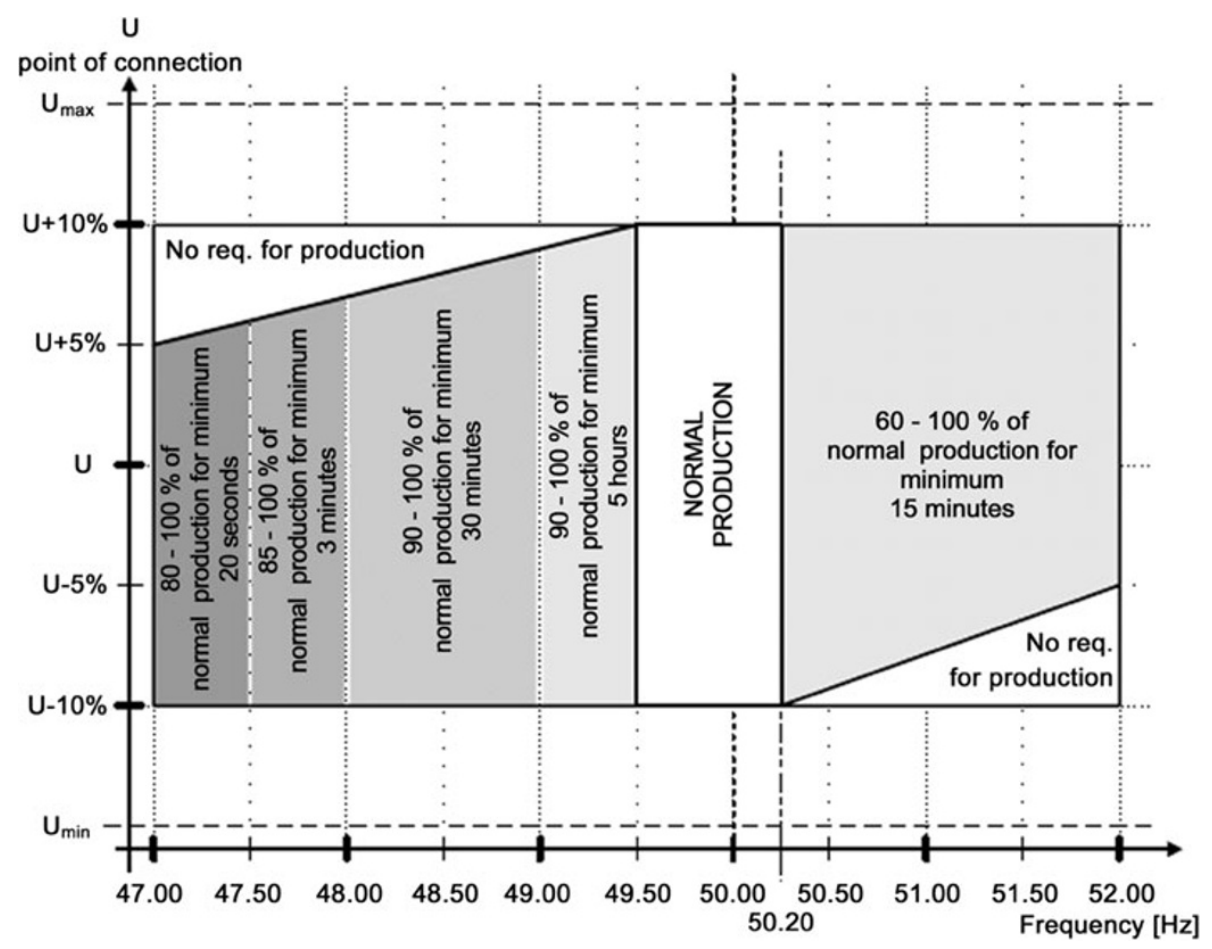

Fig. 1 Active power production requirements on frequency/voltage variations for wind power plants at $25 \mathrm{~kW}$ to $1.5 \mathrm{MW}$ [8] 


\subsection{Active power and frequency control}

To support the power system operation and control, the generation units are required to be able to increase or decrease power output with falling or rising frequency. During an over-frequency, the power output can be reduced by shutting down some wind turbines in a wind farm or by controlling wind turbines, such as pitching. On the other hand, if the wind turbine needs to increase power production in a situation of under-frequency, the wind turbines have to be previously operated at a power level lower than the available power to have some reserved power, or an energy storage system is used. Figure 2 illustrates a frequency control characteristic of a wind power plant, where $f_{1}, f_{2}, \ldots$ are specified by the system operator, and the active power is linearly regulated between $f_{1}$ and $f_{2}$, and kept unchanged with a dead band between $f_{2}$ and $f_{3}$.

Also, the active power of a wind turbine should be able to be controlled to any value within the maximum available power and the minimum power of the wind turbine.

From Fig. 3, it can be clearly seen that the demand on the reactive power capacity becomes greater if the size of the wind power plant gets bigger.

Sometime, a wind farm is required to keep the voltage at the point of common coupling (PCC) within the required range.

Early wind turbines based on conventional induction generators are normally only required to keep a good power factor, which is accomplished by switching capacitor banks or other reactive power compensation devices, such as SVC. Many modern wind generators have power electronic systems as grid interfaces, such as doubly-fed induction generators (DFIG) or full rate power electronic interfaced induction generators and synchronous generators. The power electronic systems can provide dynamic reactive power control. If more and flexible reactive power capacity is required, additional reactive power compensation systems, such as SVC and STATCOM, should be used to provide voltage support in both steady state and dynamic/transient state.

\subsection{Fault-ride through and dynamic reactive power support}

To enhance the power system security, grid codes require that wind turbines have the ability of fault-ride through, which means that the wind generators should retain the connection to electricity networks during a power system fault.

To quickly restore to normal operation after a fault is cleared, the grid codes require wind power plants to stay connected to the grid during and after a fault in the power system. Inappropriate disconnection of wind turbines from the grid may cause significant loss of generation capacity if wind penetration is high, consequently, may threaten the system security. Under the condition of a power system fault, a wind turbine would experience a voltage variation. The severity and the time period of such a voltage variation will determine whether the wind turbine must not be disconnected. Such a requirement normally has a characteristic, as shown in Fig. 4, where Area A is the normal operation zone and Area B is the fault ride through zone, i.e., wind turbines should not be disconnected from the grid if the voltage is in Area B. To help system voltage

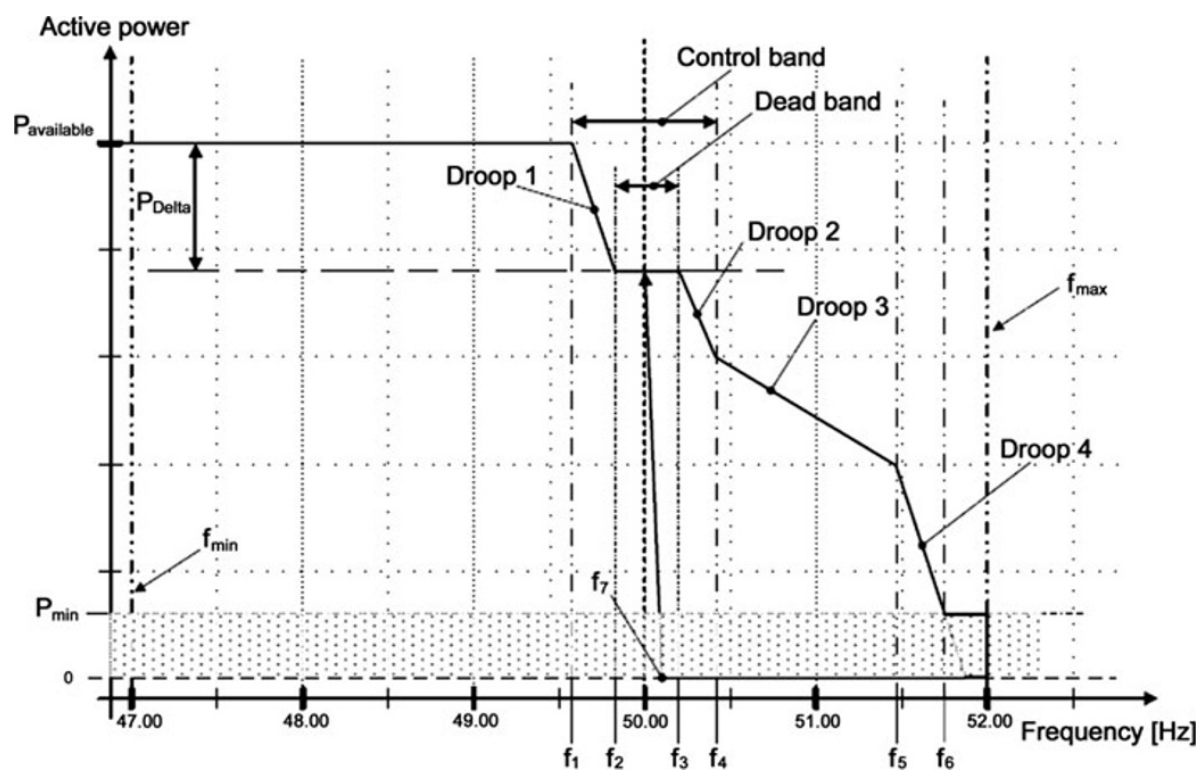

Fig. 2 Frequency control for wind power plants with a power output higher than 25 MW [8] 


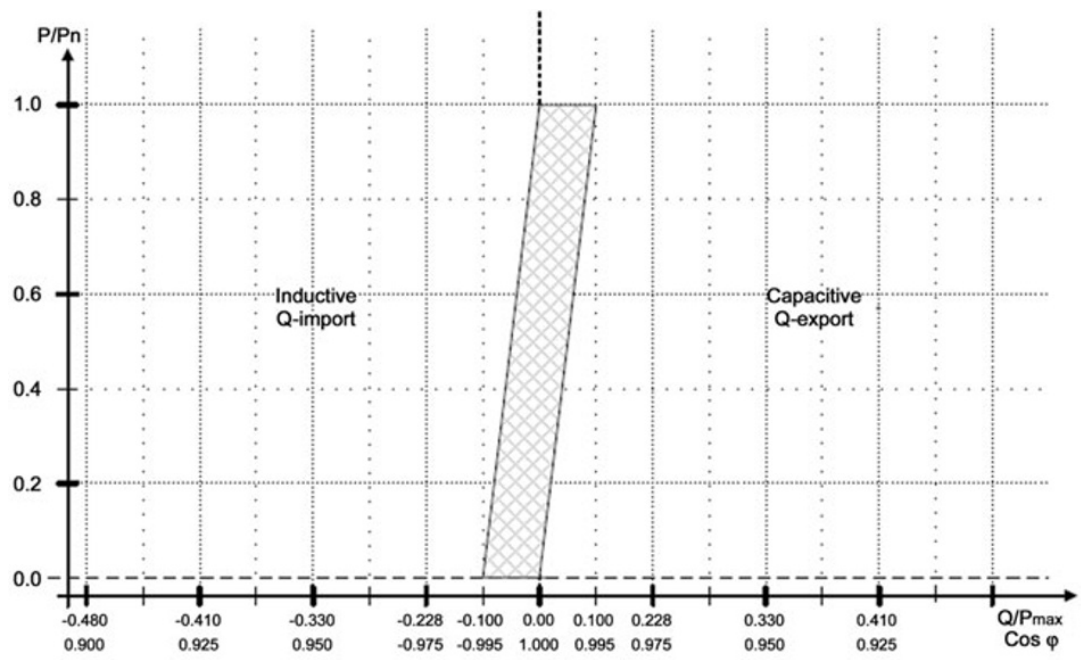

(a)

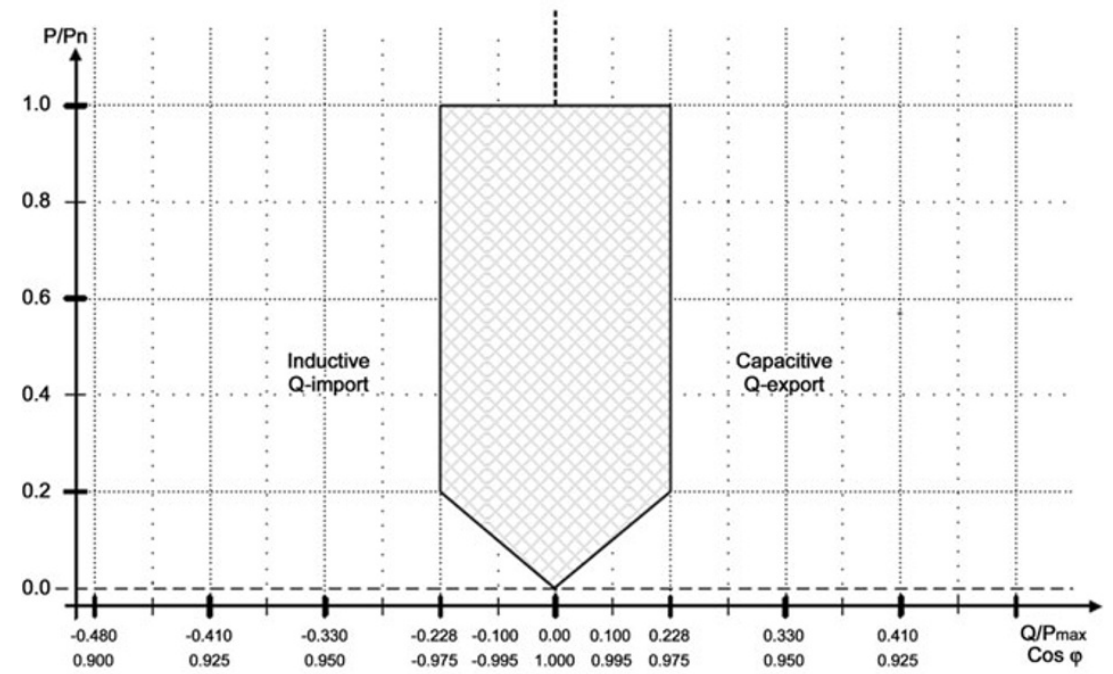

(b)

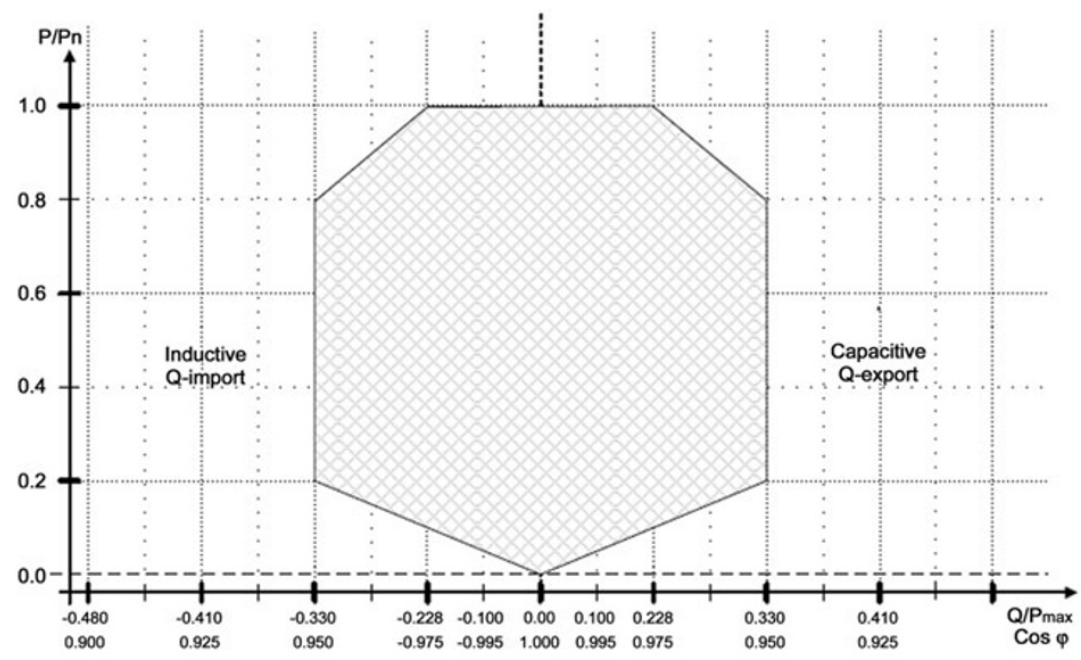

(c)

Fig. 3 Requirements for reactive power [8]. a Power range of wind turbine: $1.5 \mathrm{~kW}$ to $1.5 \mathrm{MW}$, b power range of wind turbine: $1.5-25 \mathrm{MW}$, c power range of wind turbine: $>25 \mathrm{MW}$ 


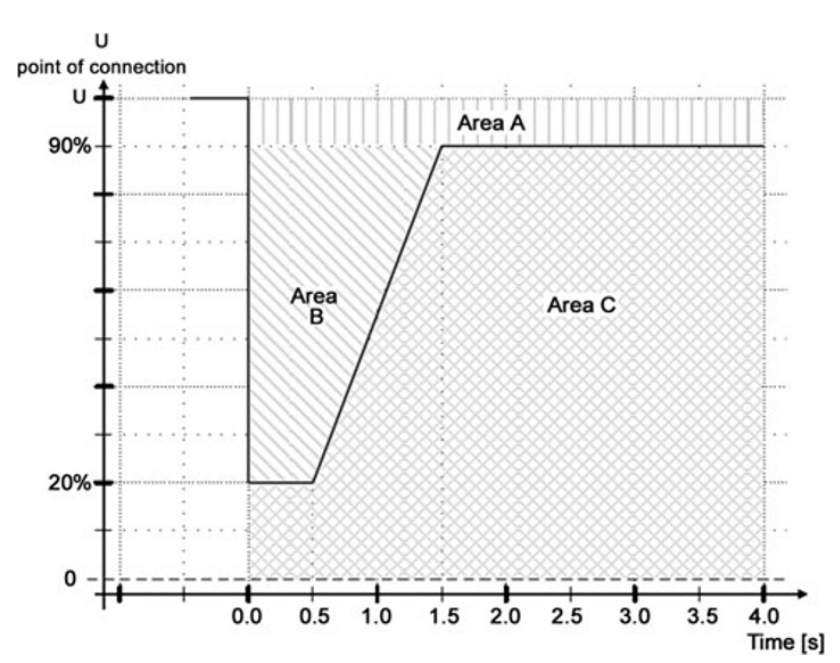

Fig. 4 Requirement for tolerance of voltage drops (power output $>1.5 \mathrm{MW}$ ) [8]

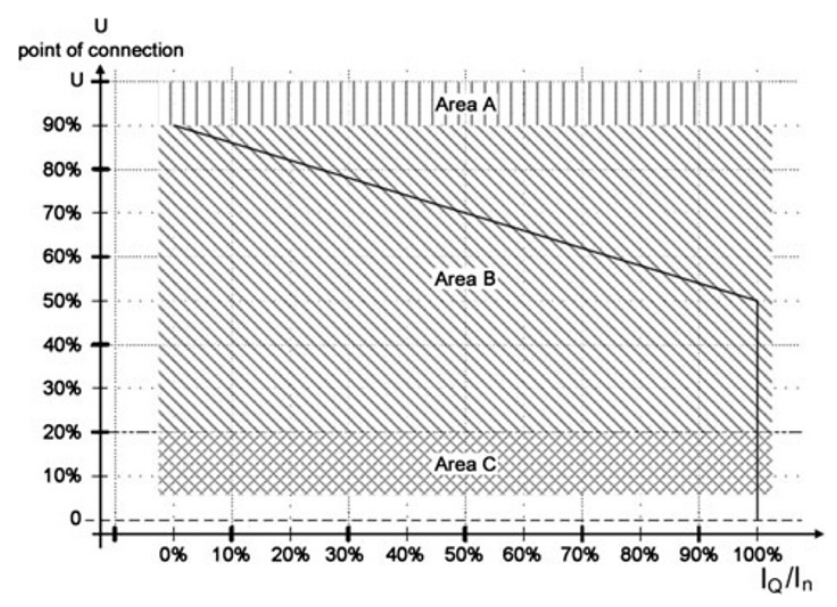

Fig. 5 Requirement for reactive power supply during voltage drops (power output $>1.5 \mathrm{MW}$ ) [8]

recovery, reactive power support is very important, and therefore is also specified by grid codes, such an example is illustrated in Fig. 5.

The grid code also requires that wind turbines have to be able to withstand more than one independent fault occurred in a few minute intervals.

\subsection{Supervisory control and data acquisition (SCADA)}

SCADA is recommended for wind power plants so that the important parameters and variables for operation and control can be communicated. In most situations, the wind farm owner is required to provide the signals necessary for the operation of the power system. Information required from wind farms generally includes voltage, current, frequency, active power, reactive power, operating status, wind speed, wind direction, regulation capability, ambient temperature, and pressure, etc.

Grid codes normally also cover power quality requirements, for example, rapid voltage variations, flickers, harmonics and inter-harmonics.

There are many different grid codes produced by power system operators in different region/countries. These regulations vary considerably from country to country. For instance, a weak power network could require more tighten fault ride-through capabilities (lower voltage and longer duration) than a robust power system.

Furthermore, a power system operator may have different requirements on its different voltage networks, there may have different grid codes, respectively for high voltage transmission system and for low-medium voltage distribution systems.

To satisfy grid code requirements, it is important to consider the solution with an overall economic efficiency, i.e., a costly technical method may result in unnecessary over-investment, which may reduce the competitiveness of wind power plants.

\section{Challenges and possible technical solutions}

It is well known that wind power plants have different features in comparison with the synchronous generators based conventional power plants, thus, the wind power penetration presents challenges to traditional grid operation and control. The significant features of wind power are as follows.

(1) Wind power is intermittent and difficult to be accurately predicted, which causes difficulties to the power dispatch and participation of electricity market.

(2) Wind power does not have a reliable availability, wind power fluctuations bring problems to power balancing, large shares of wind power increases the demand for the capacity of reserves and ancillary services.

(3) Wind power plants are less flexible and less controllable in comparison with conventional power stations.

(4) Wind power conversion system is different from conventional generators in terms of inertia, frequency- active power control, and reactive power adjustment, and power system dynamic behaviour. Therefore, different control methods are needed.

(5) Wind power plants may be located in geographically unfavourable area, far away from consumers/load centres, and large amount fluctuating power needs to be transmitted over long distance transmission lines. In the rest part of this section, some methods that can be used to address these challenges are discussed. 


\subsection{Wind power fluctuation and power balance}

\subsubsection{Wind power prediction and power system reserve}

The limited predictability of wind is a challenge. The accurate prediction of wind power is very important for wind power to perform well in the power system and market. As the percentage of wind energy in generation capacity grows, it becomes increasingly important to improve the accuracy of wind speed forecast so as to accurately predict the electricity power produced by wind farms. From the system operator's point view, a system level spinning reserve allocation among the generation units may be more cost effective if possible. Optimization of regulation and reserve power will enable the cost effective utilization of the capacity of the available generation units. Such optimization depends on the forecast accuracy of wind power and market structure. It is important to forecast the wind speed so as to estimate the amount of power generation from the wind farms, which will be used to help the planning and scheduling to meet system loads and contractual agreements. If the installed wind power capacity is larger, a small error in the wind forecast can result in a significant error in the active power prediction.

Forecast uncertainty would increase the needs for some resource capacity and ancillary services, and potentially create an opportunity for new load and ramp following services. Accurate wind speed forecast can maximize profits and minimize risks.

\subsubsection{Wind power fluctuation and interconnected networks}

Wind power fluctuates with wind speed, while the electrical grid must maintain a balance between the supply and the demand. The effects of fluctuating wind power on system regulation and stability are important issues. Large offshore wind farms may inject significant power fluctuations into power systems [9], and such power fluctuations may affect neighbouring power systems, if it is not appropriately dealt with. For example, the offshore wind farm Horns Rev A in Western Denmark produces more intense active power fluctuations than the aggregated wind power produced by land based wind farms in the western Danish power system and shows frequent active power fluctuations within periods of tens of minutes, the power gradients reach $15 \mathrm{MW}$ per minute, thus the $160 \mathrm{MW}$ wind farm have the output power change between zero and the rated power in 10-15 $\min$ [10]. The system power balance could also be worsen by the deviations from the planned power exchanges between Norway and Sweden. The total power fluctuations and deviations would be seen in deviations of the power exchange between Western Denmark and the northern Germany, the UCTE synchronous area. This situation would become more significant with the development and connection of the planned offshore wind farms in Danish Western power systems.

Expansion of wind power means additional demands on regulating power. In order to keep a power system in stable operation within the specified frequency range, the active power supplied by the generation units, including energy storage devices, must be adjusted continuously to match the varying load in the system. Such a power balance needs to consider all power exchanges related to the concerned area, for example, the deviations from the scheduled power exchange between neighbouring areas.

\subsubsection{Wind farm dispatch and virtual power plant}

A wind power dispatch centre can perform the function of controlling wind farms by sending control signals, such as reference operating points, to a wind farm controller which will perform the coordination control of the wind turbines in the wind farm, for example, responding to the frequency control, reactive power control and curtailment of wind production, etc.

An area grid controller can perform the secondary control with the central power plants and tie lines to other neighbouring power systems, including the HVDC connections [10]. The area grid controller can cooperate with wind power dispatch centre for overall system power dispatch and control to deal with the wind power fluctuations.

The fast power control of the HVDC systems is an effective way of keeping the power deviations within the specified range. Obviously, larger wind power penetration, especially, from the centralized wind farms, such as offshore wind farms, will demand higher regulating abilities of the power system. A voltage source converter (VSC) based HVDC, VSC-HVDC, can perform fast active power control and conduct reactive power control to support system voltage [11].

Local CHPs and small renewable energy source generators, wind turbines and PV systems connected to low and medium voltage level, are small in capacity of each unit, but can play an important role if a large number of such units exist in a power system, like the Danish power system. These local generation units in distribution system can be organized as a virtual power plant (VPP) to make combined contribution to the power balance of the power system and can participate in the power market.

\subsubsection{Energy storage system and flexible generation units for full use of wind power}

An energy storage device can buffer and smooth wind power fluctuation. Variable speed wind turbine can help to 
smooth out short-term spikes output, for example, running the wind turbine faster during gusts-storing energy in the same way as a flywheel.

However, large scale energy storage systems are needed to deal with long time and large scale wind power variation. Some energy storage technologies could be technically well suited for this purpose though more work is required to make those technologies competitive in economic aspect. One way of fully using the fluctuating wind power and providing a stable supply of electricity to the grid would be a combination of wind and hydropower or pump storage systems. Furthermore, the fast-controllable hydro- and gas-fired based power plants can be used for real-time balancing power in areas where a large part of electricity power is provided by non-controllable primary energy like wind energy.

Electrical vehicles with the function of vehicle to grid (V2G) and intelligent control can contribute to power smooth and efficient use of non-flexible energy source, like wind power [12].

An important feature of the future grid would be the application of energy conversion/storage units, such as electrical boilers, heat pumps, electric car batteries, hydrogen fuel cells, and other types of storages, the integration and interaction of these units with the grid will affect the economics and security of the whole energy system.

Non-electrical conversion energy systems, heat storage, can also contribute, since a heat storage system could decouple the heat production and electrical power production, therefore to give more freedom for CHPs (large thermal units or small local units) to perform power balance control.

In order to deal with the power balance, the power system may need sufficient amount of regulating power, and the appropriate arrangements of power exchange with neighbouring power systems could also ease the task.

In summary, power balance issue can be dealt with several methods, such as:

(1) Improvement of the forecast of wind speed and wind power;

(2) Provision of regulation and reserve power from other generation units (main power station and CHPs);

(3) Provision of regulating and reserve power from large wind turbines/farms;

(4) Organization of distributed generation capacities, such as a virtual power plant;

(5) Load management;

(6) Application of energy storage technologies;

(7) Establishment of appropriate power exchange facilities and agreements to utilize the regulating power control in neighbouring power systems.

\subsection{Active power-frequency control of power system}

Conventional synchronous generators, having the frequency and voltage control systems, can automatically adjust the productions of active and reactive power with the variations of frequency and voltage.

In a power system, the frequency will change in response to an imbalance between the supply and the demand, then the primary and secondary controls are activated to reduce the power imbalance and to bring the frequency back in the specified range. Conventional generation units are normally equipped with a governor control, which works as primary load frequency control. In order to restore the frequency to its nominal value, the secondary control is employed to result in an increase or decrease of power production of the relevant generators. Also, a rotational generator has the nature to against the speed variation by storing or releasing its kinetic energy in response to the frequency variation, which is the inertia effect.

Wind turbines should contribute towards stable grid operation. To enable a variable-speed wind turbine, such as a full rate power electronic system interfaced wind turbine, to contribute to the system inertia and frequency control, a control method may be used to directly adjust the turbine output power in response to the frequency variation. For example, the wind turbine increases its power output to the grid during a frequency drop. However, such a wind turbine system needs either to be operated below the available wind power level or to be equipped with an energy storage system.

Wind farm may actively participate in grid management, including provision of regulating power. In order to deal with large scale power fluctuations, some spinning reserve may have to be kept in wind turbines. Similar to that as mentioned above, for any action requiring an output power increase, the wind turbine may have to operate at a power level lower than the available power level, which means a reduced utilization of the wind energy, and hence reduced revenues.

Furthermore, fast-start flexible generation units, such as diesels, can effectively help the frequency and power control.

Whilst the wind farms are considered like other generating facilities to participate in the system frequency control, an overall economically efficient solution should be searched for an overall optimization to decide how to distribute the primary and secondary control capacity among conventional power plants, wind farms and possible energy storage systems.

\subsection{Wind power transmission and weak grid operation}

It is clear that the sufficient transmission capacity is needed to carry the remotely generated wind power to the 
demand centres. This capacity must be provided by transmission networks.

In some area, the power system may not be designed to transfer the quickly increased large scale wind power, consequently, the wind power transmission may be limited by the power system constraints and bottlenecks. Actions have to be taken to handle grid congestion and constraints violation. Some possible solutions include the grid reinforcement and expansion, wind power curtailments and energy storage. The optimal location of wind farms can also contribute to the alleviation of the power transfer limitation [13].

The utilization of existing power lines can often be increased by operating them at a higher capacity, assisted by temperature monitoring. Improving the cross-border electricity exchange manner, and thus the way of power exchange between different networks, is also a method for alleviating congestion. If controllable power plants are available within the congested area, coordinated automatic generation control (AGC) is applied. Demand-side management, according to the wind energy and transmission situation, is another option.

There are also other ways of increasing the transmission capacity of the network, including:

(1) Increase system capacity by increasing voltage level, adding transformers or new lines, or using high temperature conductors;

(2) Improve the power flow distribution in the network to fit better with the line capacities, for example, by installing new facilities, like series reactors, phase shifting transformers, or devices to increase voltage support (shunt reactive, such as static VAR compensators).

Grid reinforcement may be necessary to maintain adequate transmission, as wind power penetration increases. The construction of new lines may also be a prerequisite for reaching regions with a high wind resource. However, in some areas, the construction of the required network upgrades, especially new lines, may be a very lengthy process.

A wind farm may connect to a weak grid which has a low short circuit capacity, so that the short circuit ratio (SCR), the grid short circuit capacity/wind farm capacity, is low, that tends to give power quality and stability problems, because wind turbines may not be designed for such a situation. The problem may be mitigated by tuning the wind turbine/farm controllers, using wind turbine power electronic interface [14], installing reactive power compensation devices and network enhancement.

\subsection{Wind power curtailment}

Reinforcing a transmission network can completely remove a bottleneck, however it may not be economically justified. Because the full load hours of wind turbine generator are only $2,000-4,000 \mathrm{~h}$ per year, which means that the wind turbines operate below their power rating at most time, and also wind power turbines are not necessary to reach their rated values at the same time.

Therefore, wind power curtailments during congestion situations is considered as another solution for large-scale wind power integration with less or no grid reinforcement [15], though the curtailment is both environmentally and economically inefficient, which means the revenue loss of the wind farm owner. Wind power curtailment may be achieved through either manual curtailment, AGC or frequency control, which is used to stabilize the grid frequency. Ideally, curtailment of wind power production should be managed from an overall optimization point of view.

\subsection{Power grid interconnection and offshore super-grid}

The power produced from a large number of wind turbines will fluctuate relatively less than the power produced from a single wind turbine due to the cancellation effect. A large geographical spread of wind power generation will reduce variability, increase predictability and decrease the occurrences of near zero or peak outputs. Geographical averaging is very useful to smooth wind power variations in all time-scales. If more wind turbines are in a system which covers a wider area, the time scale of the wind power fluctuation is longer. In fact, as the wind may always blow somewhere, a lower level of power output at a single wind farm can be balanced by a simultaneous high output power from another wind farm several hundred kilometres away.

A European super-grid concept is proposed to accommodate large amounts of offshore wind power and to utilize continental-wide smoothing effects of wind power to a maximal extent $[16,17]$. An ocean super-grid, an example as illustrated in Fig. 6, will create a network between a number of countries to balance the fluctuations of wind energy and to solve the problem of the variability of wind, can turn the fluctuating wind energy source into a quite stable power source [18], while some dispatchable power sources located in long distance, such as hydro-power generation units, can be used to keep an overall stable power supply.

Furthermore, the emerging internal electricity market in Europe requires an adequate transport capacity among different power market zones to enable effective competition and trade of electricity. Therefore, enhancing the suitability of the grid for the increased inter-market electricity transport is important for both the wind industry and electricity market development. The super-grid could have an important function in distribution and transmission of 


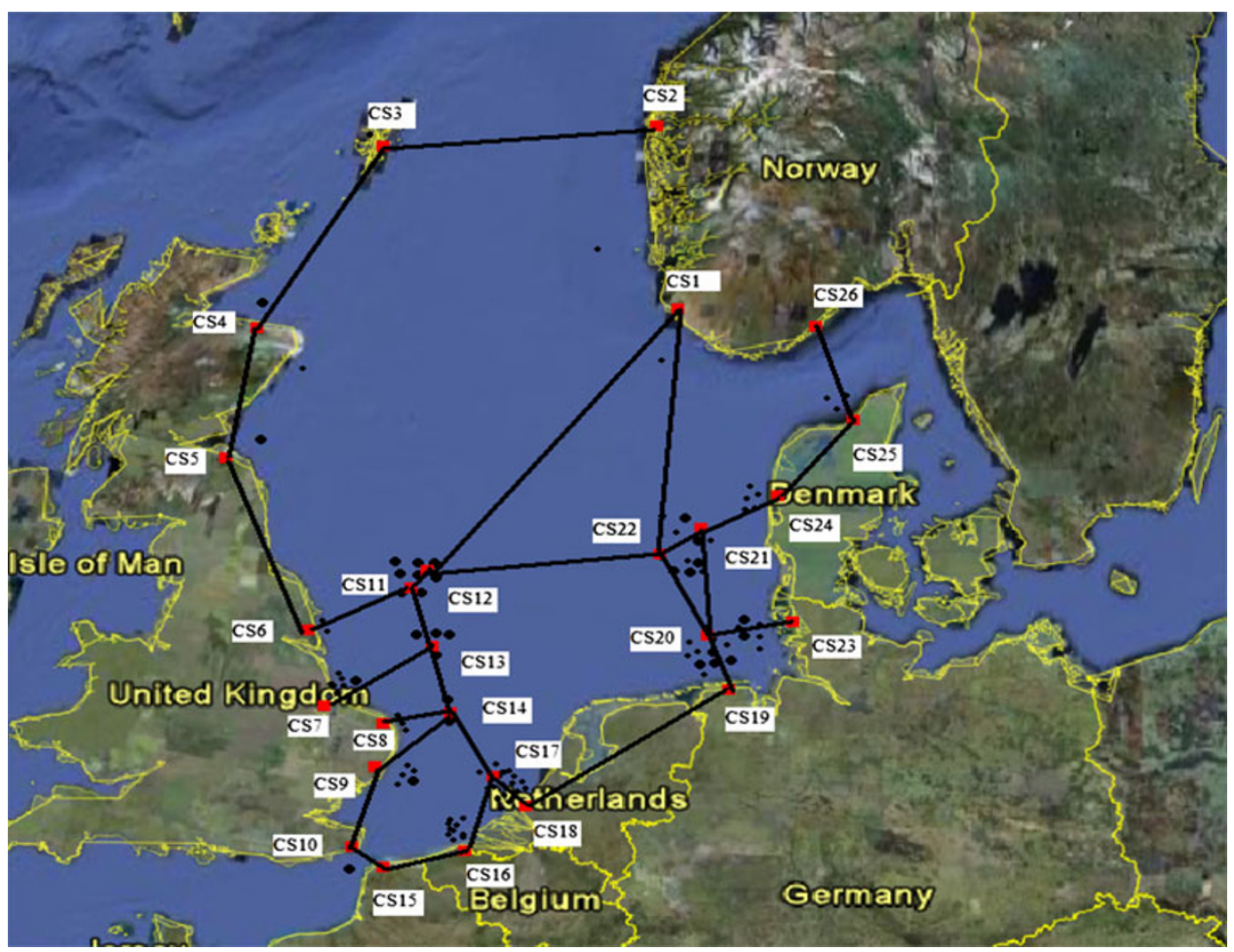

Fig. 6 Possible offshore super-grid in North Sea [18]

renewable energy between the countries and it can introduce additional flexibility to the power system operation and control.

\subsection{Reactive power and voltage control}

The voltage is closely related with reactive power, thus the wind turbines with the ability of controlling reactive power can support system voltage control. As indicated in grid codes, large wind farms are required to have the ability of controlling both active and reactive power. The simplest way of controlling reactive power is to use switched capacitor banks.

For the wind farm with the fixed speed wind turbines equipped with conventional induction generators, the active power production and the reactive power absorption are strongly coupled. Thus, the active power fluctuations can result in similar fluctuations of the reactive power absorption, consequently, the appropriate dynamic reactive power compensation equipment is needed to smooth the possible voltage fluctuations.

For power electronics interfaced wind turbines, the power electronic converters can be controlled to contribute to reactive power control [5]. Reactive power can be controlled to compensate the voltage variation caused by active power fluctuations, so that the fluctuations of the grid voltage at the connection point of the wind farm can be limited within the specified range. Also, the reactive power related to the wind power collection network can cause voltage variations, which needs to be considered.

Furthermore, for a large scale wind farm, a central reactive power compensation device, such as SVC or STATCOM can be used to provide smooth voltage regulation at point of common coupling (PCC).

At significant penetration levels, a wind power plant may be required to contribute to voltage management in the grids, which can be achieved by devices, such as FACTS, and coordination of other power generation units in the system.

The power electronics in modern wind turbine systems can naturally enhance the interaction between the grid and the wind power plant, and provide smooth reactive power regulation to the grid.

\subsection{Wind turbines in power system transients-fault ride-through and stability support}

System stability is normally associated with power system faults in a network, such as tripping of transmission lines, loss of production capacity (generator unit failure) and short circuits. These failures disrupt the balance of power (active and reactive) and change the power flow. Though the capacity of the operating generators may be adequate, large voltage drops may occur suddenly. The 
unbalance and re-distribution of active and reactive power in the network may force the system variables to vary beyond the boundary of stability. A period of low voltage (brownout) may occur and possibly be followed by a complete loss of power (blackout).

During a short-circuit fault in a power system in which the wind turbines are connected, the short circuit current may result in a voltage drop at the wind generator terminal. Due to the voltage dip, the output electrical power and the electromagnetic torque of the wind turbine are significantly reduced, while the mechanical torque may be still applied on the wind turbine. Consequently, the turbine and generator will be accelerated due to the torque unbalance.

After the fault clearance, the voltage tends to recover. If the voltage is not able to return to normal range or the generator speed is too high, there may be no sufficient electromagnetic torque to balance the mechanical torque. Hence, the machine would continue to accelerate. If this happens, the wind turbine may have to be disconnected, thus fails to ride-through the fault. Such wind turbine disconnection should be avoided because losing a significant part of the power generation capacity could threaten the security of the power system.

To ensure the security of a power system with high wind power penetration level, the fault ride through (FRT) capability of wind turbines is required, various methods may be used for different types of wind turbines [19-21], the FRT capability and system stability can be improved by:

(1) Dynamic reactive power compensation;

(2) Fast power control;

(3) FACT devices to provide reactive power and minimize voltage dip;

(4) Wind turbine protection and control;

(5) Fast response energy storage system.

\subsection{Wind power plant control}

With the increase of wind power penetration, wind power plants have to take over the role of conventional generators in some network. Consequently, it will become necessary that wind power plants (WPPs) could be controlled like conventional generators to contribute to voltage and frequency control. A two level hierarchical structure, consisting of a wind power plant controller and wind turbine controllers, may be used. The wind farm controller communicates with higher level control centre and determines the operating points for wind turbines to meet grid demands. The turbine controller responds to the power set point from WPP controller.

However, due to the relative large area where wind turbines are distributed in a wind farm, some significant differences exist, a WPP may consist of a large number of wind turbines, which need to be coordinatively controlled and monitored. That requires great computational effort and modern control hardware; also, the communication delay between the wind turbine generator and the wind power plant controller should be considered to avoid possible instability. Fast and accurate set point tracking is essential for the efficacy. The control strategy design should consider the prevention of oscillations and unstable situation.

\subsection{Power oscillation damping}

The fluctuating wind power, including $3 \mathrm{p}$ component, may excite or amplify power system oscillations, several studies have investigated the impacts of wind power on power system oscillations [22-25], and small signal stability [26].

The active and reactive power of a WPP can be controlled to damp power system oscillations. Several power oscillation damping controllers have been studied, including active power modulation, reactive power modulation, and a combination of both active power and reactive power modulation. Such a damping controller may be implemented with the WPP controller. The wind turbine mechanical resonance frequencies may be within the typical range for power system oscillations, which may limit the frequency range; then an active power modulation controller should be used to avoid exciting oscillations at mechanical resonance frequencies of the wind turbine.

The damping controller can be designed in a similar way as synchronous machine power system stabilizers (PSS) with reactive power modulation on the WWP or additional FACTS devices.

\section{Wind power and electricity price}

Wind power may participate in electricity market as conventional generators. Figure 7 shows four levels of wind power production and the corresponding power prices depicted for each hour during a day. The curve of '0-150 MW' approximates the prices for the situation without wind power. The other curves show different levels of wind power productions. It can be seen that higher the wind power production, the lower the electricity price $[27,28]$. The general relationship between the electricity price and wind power is illustrated in Fig. 8.

A typical example for electricity supply and demand is shown in Fig. 9 [29, 30], where the cost-supply curves of different types of generation units are illustrated. The nuclear and wind power units are located in the lowest part of the supply curve, followed by combined heat and power plants, then condensing plants, and gas turbines have the highest marginal costs. While, the hydro-power dispatch depends on the reservoir management which is not shown. 


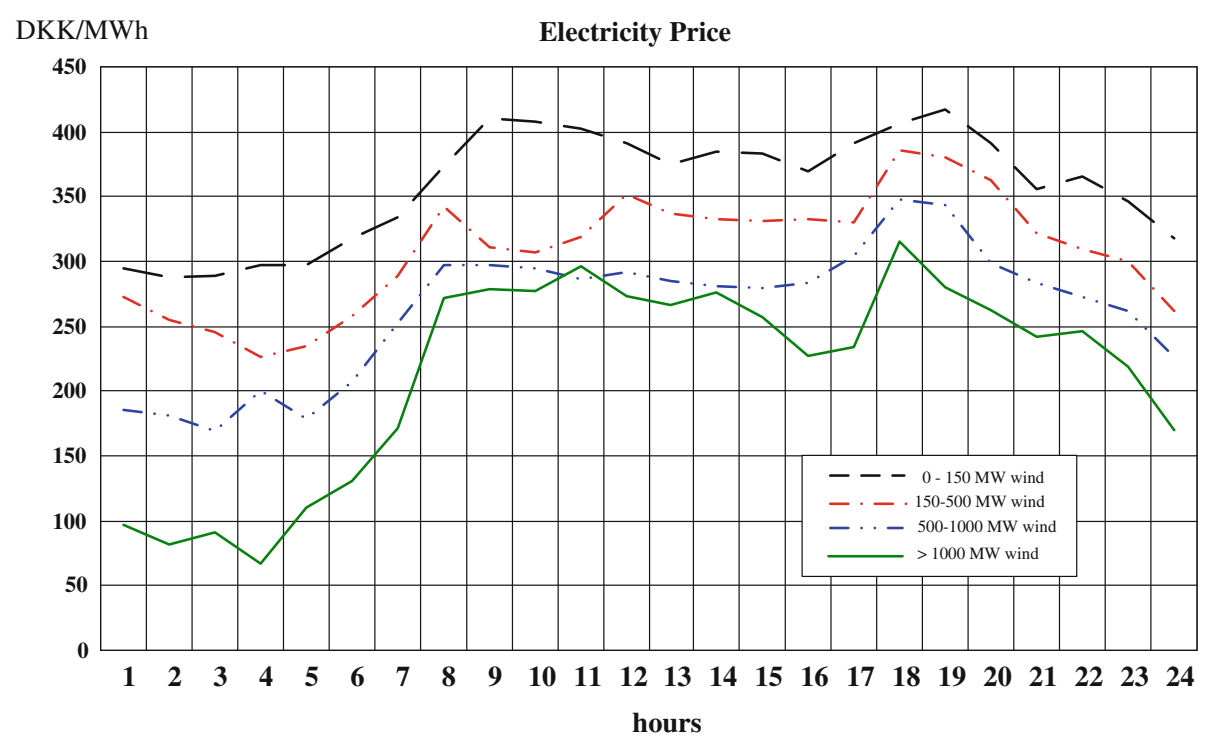

Fig. 7 Electricity price variation during a day (Source: Dong Energy)

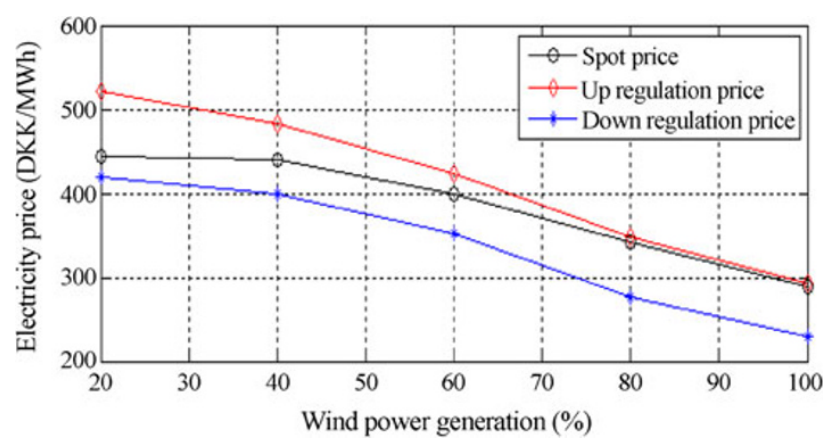

Fig. 8 Relationships between electricity price and wind power production

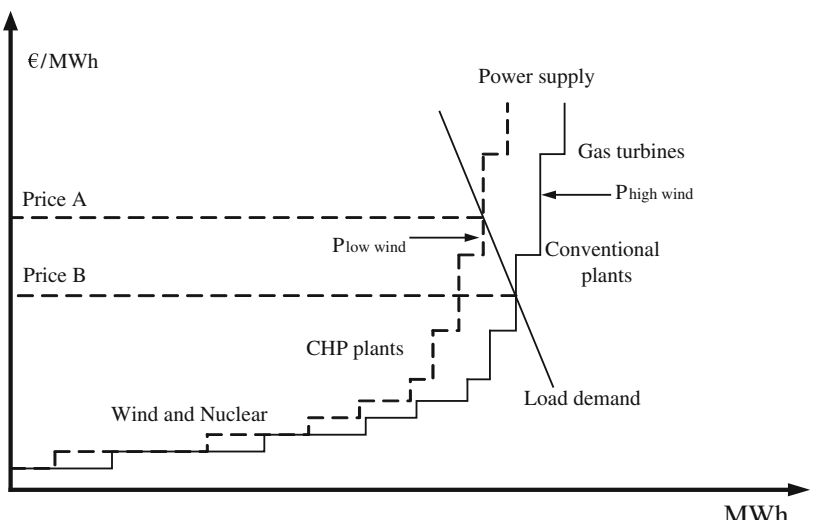

Fig. 9 Relationships between electricity price, supply and demand (Source: Risø DTU)

In general, the electricity price is expected to be lower during high wind periods, so that higher wind power can shift the supply curve to the right area in Fig. 9. However, the impact of wind power depends on the load level. If there is plenty of wind power during the peak power demand, wind power may significantly reduce the power price (from Price A to Price B). However if a high wind production happens during a low power demand period, where the most power is produced by base load plants, the impact of wind power on the electricity price would be low.

There may be congestions in power transmission, especially during periods with high wind power generation. If the available transmission capacity cannot allow the power transmission freely as load demand, the constrained line may separate the area into two independent pricing areas. In the area with excess supply of power, the electricity price could be lower.

\section{Conclusion}

Integration of large scale wind power into power systems has many challenges. Wind turbines/farms are required to behave in a similar way to conventional power stations. This paper describes some main requirements of grid codes for wind turbine connections, then discusses the major challenges and possible technical solutions. Finally, it has briefed the influence of wind power on electricity price.

Open Access This article is distributed under the terms of the Creative Commons Attribution License which permits any use, distribution, and reproduction in any medium, provided the original author(s) and the source are credited.

\section{References}

[1] Pure power-wind energy targets for 2020 and 2030 (2011). European Wind Energy Association 
[2] A visionary Danish energy policy 2025 (2007). Danish Energy Authority

[3] 50\% wind power in Denmark in 2025-English summary (2007). Ea Energy Analyses, Copenhagen, Denmark

[4] China wind energy development roadmap 2050 (2011). Energy Research Institute, Beijing, China

[5] Chen Z, Guerrero JM, Blaabjerg F (2009) A review of the stateof-the-art of power electronics for wind turbines. IEEE Trans Power Electron 24(8):1859-1875

[6] Chen Z, Blaabjerg F (2009) Wind farm-a power source in future power systems. Renew Syst Energ Rev 13(6/7):1288-1300

[7] Chen Z (2005) Issues of connecting wind farms into power systems. In: Proceedings of the 2005 IEEE/PES transmission and distribution conference \& exhibition: Asia and Pacific, Dalian, China, 14-18 Aug 2005, 6p

[8] Technical regulation 3.2.5 for wind power plants with a power output greater than $11 \mathrm{~kW}$. Document no 55986/10, Technical Regulation 3.2.5, Energinet.dk, 2010

[9] Chen P, Chen Z, Bak-Jensen B et al (2007) Study of power fluctuation from dispersed generations and loads and its impact on a distribution network through a probabilistic approach. In: Proceeding of the 9th international conference electrical power quality and utilisation (EPQU'07), Barcelona, Spain, 9-11 Oct 2007, 5p

[10] Akhmatov V, Rasmussen C, Eriksen PE et al (2007) Technical aspects of status and expected future trends for wind power in Denmark. Wind Energ 10(1):31-49

[11] Liu Y, Chen Z (2011) Power control method on VSC-HVDC in a hybrid multi-infeed HVDC system. In: Proceeding of the IEEE power and energy society general meeting (PES'12), San Diego, CA, USA, 22-26 July 2012, 8p

[12] Hu WH, Wang XR (2011) Analysis for large scale integration of electric vehicles into power grids. J Electr Power Sci Technol 26(4):14-19 (in Chinese)

[13] Siano P, Chen P, Chen Z et al (2012) Optimal allocation of wind turbines in active distribution networks by using multi-period optimal power flow and genetic algorithms. In: Wang L (ed) Modeling and control of sustainable power systems, green energy and technology. Springer, Berlin, pp 249-268

[14] Diedrichs V, Beekmann A, Busker K et al (2012) Control of wind power plants utilizing voltage source converter in high impedance grids. In: Proceedings of the IEEE power and energy society general meeting (PES'12), San Diego, CA, USA, 22-26 July 2012, 9p

[15] Siano P, Chen P, Chen Z et al (2010) Evaluating maximum wind energy exploitation in active distribution networks. IET Gener Transm Dis 4(5):598-608

[16] Woyte A, De Decker J, Thong VV (2008) A north sea electricity grid evolution. Report. Greenpace, 3E, Brussels, Belgium

[17] Groeman F,Moldovan N, Vaessen P (2008) Ocean grids around Europe.White paper. Kema, Leonardo Energy

[18] Grimaldi A, Chen Z, Chen P et al (2011) Designing offshore super grid for the combined operation of offshore wind farms and hydro storage. Int J Power Syst Optim 2(1):149-158

[19] Sun T, Chen Z, Blaabjerg F (2005) Transient stability of DFIG wind turbines at an external short-circuit fault. Wind Energ $8(3): 345-360$
[20] Seman S, Niiranen J, Arkkio A (2006) Ride-through analysis of doubly fed induction wind-power generator under unsymmetrical network disturbance. IEEE Trans Power Syst 21(4):1782-1789

[21] Chen Z, Hu Y, Blaabjerg F (2007) Stability improvement of induction generator-based wind turbine systems. IET Renew Power Gener 1(1):81-93

[22] Hagstrom E, Norheim I, Uhlen K (2005) Large-scale wind power integration in norway and impact on damping in the nordic grid. Wind Energ 8(3):375-384

[23] Slootweg J, Kling W (2003) The impact of large scale wind power generation on power system oscillations. Electr Power Syst Res 67(1):9-20

[24] Tsourakis G, Nomikos B, Vournas C (2009) Effect of wind parks with doubly fed asynchronous generators on small-signal stability. Electr Power Syst Res 79(1):190-200

[25] Knüppel T, Kumar S, Thuring P et al (2012) Towards a reactive power oscillation damping controller for wind power plant based on full converter wind turbines. In: Proceedings of the IEEE power and energy society general meeting (PES'12), San Diego, CA, USA, 22-26 July 2012, 8p

[26] Su C, Chen Z (2012) Influence of wind plant ancillary frequency control on power system small signal stability. In: Proceedings of the IEEE power and energy society general meeting(PES'12), San Diego, CA, USA, 22-26 July 2012, 8p

[27] Smolen J, Chen Z (2012) Explanation of price peaks on Danish electricity market. In: Proceedings of the 9th international conference on the European energy market (EEM'12), Florence, Italy, 10-12 May 2012, 7p

[28] Hu WH, Chen Z, Bak-Jensen B (2012) Analysis of electricity price in Danish competitive electricity market. In: Proceedings of the IEEE power and energy society general meeting (PES'12), San Diego, CA, USA, 22-26 July 2012, 8p

[29] Moesgaard R, Morthorst PE (2007) The effect of wind power on spot market prices. In: Proceedings of the European wind energy conference and exhibition (EWEC'08), Brussels, Belgium,31 Mar-3 Apr 2008

[30] The economics of wind energy (2009). The European Wind Energy Association

\section{Author Biography}

Zhe CHEN received the B.Eng. and M.Sc. degrees from Northeast China Institute of Electric Power Engineering, Jilin City, China, and the $\mathrm{Ph} . \mathrm{D}$. degree from University of Durham, U.K. He is a full Professor with the Department of Energy Technology, Aalborg University, Denmark. He is the leader of Wind Power System Research program at the Department of Energy Technology, Aalborg University, and the Principal Investigator of Wind Energy at SinoDanish Center for Education and Research. His research areas are power systems, power electronics and electric machines; and his main current research interests are wind energy and modern power systems. 